\title{
Practice Educators in an Uncertain World: Still Too Much to Ask?
}

\author{
Vinette Cross ${ }^{1,2}$ \\ ${ }^{1}$ Centre for Health and Social Care Improvement, School of Health and Wellbeing, Wolverhampton \\ University, Deanery Row, Wolverhampton WV1 1DT, UK \\ ${ }^{2}$ Clinical Research Centre, School of Health Professions, University of Brighton, Eastbourne BN20 7UR, UK
}

Corresponding author:

Vinette Cross, Senior Research Fellow, Clinical Research Centre, School of Health Professions, University of Brighton, Aldro Building, Darley Road, Eastbourne, East Sussex BN20 7UR, UK

Email: Vinette.cross@wlv.ac.uk, Phone: +44 (0) 1273643647

\section{Abstract}

In recent times the complexity and ever-evolving nature of health and social care systems have reshaped professions and rendered the future uncertain. Fast moving social, economic and technological changes have redefined the various roles of practitioners and educators alike. There is a danger that standing on shifting sands may have an adverse effect on the quality and outcomes of learning relationships at all levels of learning and professional development. Nearly two decades ago I suggested that yet another role shift in response to yet another policy change was 'too much to ask' of hard pressed practitioners involved in delivering professional education. As the world of health and social care remains uncertain and unpredictable, this paper looks at some of the challenges facing practice-based educators in 2013.

Keywords: practice-based education, professional learning, allied health professions, social care

\section{Introduction}

The tasks of supporting and assessing the learning of others in the workplace are common to all members of health and social care practitioners across disciplines. Although labelled differently, for example practice educators (occupational therapists), clinical educators (physiotherapists), practice teachers/assessors (social work and specialist community nurses), mentors (nursing and midwifery) in the United Kingdom (UK), the challenge for hard-pressed practitioners is equally daunting. In recent times the complexity and everevolving nature of health and social care systems have reshaped professions and redefined the various roles of practitioners and educators alike. Hence the view that 'education is something we neither give nor do to our students; it is a way we stand in relation to them' (Daloz 1999) assumes particular resonance. Despite a danger that standing on shifting sands may have an adverse effect on quality and outcomes, potentially these are exciting times for practice educators: widening participation in professional education across disciplines, greater diversity in types and levels of educational programme creating a new 
demographic of adults learning in the workplace, new initiatives such as student-run training wards, preceptorship, and interprofessional learning, innovative use of information and communication technologies in assessment and feedback, and direct service user involvement in educational processes.

Nearly two decades ago in the centenary year of the Chartered Society of Physiotherapy, I suggested that practitioners involved in student learning seemed to have 'stumbled through a variety of roles, each teetering precariously on the one before' (Cross 1994). However, professional bodies were united in asserting practitioners' moral and professional responsibility to develop their own competence as educators as well as practitioners. At the time I wondered whether another role shift, from 'clinical supervisor' to 'clinical educator', in response to yet another policy change, was 'too much to ask'; whether 'survival' rather than 'development' was the word of choice. In 2013 practitioners strive to function in an even more uncertain and unpredictable world, in which an unstable job market and threats to patient/client safety are dominant issues globally. Therefore, it seems timely to revisit some of the issues facing practitioners caught up in the professional education endeavour. Now the role of practice educator (the term used here to denote all those described above) has acquired greater clarity and acceptance. Indeed, in its strategy document 'Developing People for Health and Healthcare', Health Education England (HEE 2013) proposes that involvement in training and education should be a 'badge of honour' for practitioners (p4). In the UK, as elsewhere, a range of provision exists within higher education institutions (HEI) designed to develop health and social care practitioners as educators. These encompass discipline specific structures for accreditation of educator status, for example, Accredited Clinical Educator Status (ACE) in physiotherapy, and Accreditation of Practice Placement Educator (APPLE) in occupational therapy. Nevertheless, while the imperatives for professional development seem apparent, preparation and support for this vital role remain inconsistent, subject to funding and time restrictions and to the vagaries of organisational and workplace culture. Yet practice educators must find a way through such difficulties, taking account of the diversity of world views held by students, practitioners, organisations and the public in order to improve their own performance as educators, their contribution to professional learning and the quality of service users' experience.

[A]dult educators like other workers are increasingly positioned as being required to be flexible and reflexive, innovative and creative, dynamic in their responses to and engagements with changed circumstances, able to locate, map and translate the different discourses in their arena of practice... These characteristics are to be instilled through professional development.

(Nicoll \& Edwards 2012, p237)

Giddens (1991, p61) has argued that as traditional frameworks of society are reconfigured a position of reflexivity is required, which means that 'we are constantly responding and adjusting to the changing environment around us ... we evolve with and within the larger context in which we live.' In this spirit, Boud \& Hager (2012) suggest a reframing of practice as conceptualising any human activity. Rather than simple application of knowledge, or inevitable consequence of learning, 'the notion of practice provides a holistic way of thinking that integrates what people do, where they do it, with whom and for what purpose' (Boud \& Hager 2012, p22). Practices evolve and are transformed within historical and social contexts and, as a corollary, so do the professional identities of practitioners engaged in those practices. In what follows the concept of 'discourse community' is used to examine some of the challenges faced by professional practitioners in 2013, and the implications for their positioning as educators in the workplace. 


\section{Discourse communities as a basis for reflection on practice education}

In this sense community refers to an association of individuals seeking ways to interpret their experiences and build a collective identity that reinforces their common issues without effacing their differences. Discourse interweaves language, action and identity and the notion of discourse community is a way to consider how social pressures may impinge on the practices of individuals (Romero 1998, Ovens 2002). Discourse communities may be embedded within broader communities of practice, and members may navigate between different communities, possibly with conflicting loyalties, but often with varying degrees of overlap. Three overlapping discourse communities are described below, and in terms of the practice educator this overlap is an important feature. However, they are presented as discrete entities so as to highlight the salient issues within each.

\section{The pedagogical discourse community}

There is general consensus that pre-registration education is only the beginning of learning that continues throughout a professional career (Hager 2004, Dall'Alba \& Sandberg 2006, Billett 2008, HEE 2013). Thus members of this discourse community share a concern to position themselves in relation to differing conceptions of learning in the workplace, what makes that learning productive, and what pedagogies enhance this. An important question is, 'What does it mean to be a learner in the workplace?' From one perspective focusing attention on performance outcomes, as evidenced through competency frameworks and acquisition of generic skills such as communication and problem solving, conceptualises learning as a product. Learners are stereotyped, addressed and measured only through pre-identified learning needs and learning outcome statements (Hughes 2002). Discrete, decontextualised elements, once acquired, can simply be transferred and replicated in diverse situations (Hager 2004). The expectation is that learners achieve the same level of attainment. Their task is to navigate the assessment system. They are important insofar as they can be moulded into efficient workers capable of efficient execution of production. The implication is that to be a learner is to be deficient or incompetent, which may lead to practitioners exaggerating their own knowledge and learners' lack of knowledge (Gardner 1994). Thus, the learner's aim is to shed the label as quickly as possible.

Alternatively, seeking a nourishing relationship focuses attention on learning as a process of 'becoming' rather than as a product: becoming a physiotherapist, rather than doing physiotherapy. Such a transformative view points to the organic, whole person nature of learning, to the construction of a professional identity as well as the acquisition of knowledge and skills (Hager 2004). A seminal theorist on learning as a process, Dewey (1916) saw its value in terms of the extent to which it creates a desire for continued growth, and a capacity to readjust constantly to the environment. Understanding of central concepts and the links between them deepens gradually over extended periods of time. 'As learners come to incorporate more complex and diverse information into their intellectual vision, they tend to seek more of the same,' (Daloz 1999, p44). In this conception Hager suggests that transfer of learning broadens from replicability into preparation for future learning and the ability to learn in new environments. Thus, to be a learner is a desirable, career-long role. These two conceptualisations give rise to reflective questions such as: 'What is my personal philosophy as an educator?' 'Where do I position myself in relation to learning as product and learning as process?'

\section{The critical discourse community}

Since 1994 health and social care practitioners have been bombarded with calls for public accountability, and educators in the academy and in practice have not been immune. In this 
changing landscape the players talk about themselves, their relationships and purposes in different ways (Ball 2003); ways that change not only what they do, but who they are. Practitioners are 'service providers', patients and clients are 'service users'. Learners on programmes at all levels are 'consumers of education'; interactions are defined in terms of partnership, negotiation, collaboration and facilitation. At the same time a drive for accountability sees professionals (academics, teachers, health and social care practitioners, researchers etc.) subject to a daunting array of judgements, measures, comparisons, and inspections by a multitude of professional and government agencies (Ball 2003, Gilbert 2005). As a result, Ball suggests, a culture of 'performativity' has been created, in which purposes and motivations are blurred; a conflict of values is created, 'where commitment, judgement and authenticity within practice are sacrificed for impression and performance' (Ball 2003, p220). In such circumstances practitioners feel anxious and unsure about the judgements that lie behind their actions. 'Do I do this because it is important, I believe in it, it is worthwhile, or because it will be measured?' 'How do I know I am good at what I do?' For practice educators the tension between their educator and practitioner roles may intensify anxiety in terms of which has the greater perceived value or priority. Reflective questions for this discourse community are: 'Why do I do what I do as an educator?' 'In preparing learners for the challenges of practice can I reconcile competing value systems and practise authentically as an educator (as well as a clinician)?'

\section{The situated learning discourse community}

The situated nature of learning and the central role of participation are evident across theories of learning in the workplace (Lave \& Wenger 1991, Rogoff 1995, Billett 2001, Fuller et al. 2005). The question for this discourse community is 'What do we mean by authentic professional learning?' Billett \& Somerville (2004) postulate a situation in which individuals take up work for pragmatic reasons but go on to experience a growing passion and commitment. They suggest that this process, in which work becomes part of their sense of self, begins early in a career.

The conscious process of engaging in activities and interactions that secures knowledge is not separable from changes to (individuals') knowledge: learning. This process is both shaped by, and in turn shapes, individual identities (Billett \& Somerville 2004, pp313-314).

The more individuals see themselves represented in the work they do, the greater their engagement and the greater the level of learning that occurs through participation. This process is rooted not just in specific learning moments or contrived events but in social interaction, and the professional activity of reflection (Schon 1991). Such socially situated reflection, as opposed to solitary rumination on experience, is shaped and constrained within particular cultures and historical contexts, such as those already described. Recognition and valuing of this identity shaping process, in their interactions with pre-registration and entry-level learners, should be a particular concern for practice educators. Webster-Wright (2009) argues that authentic professional learning is as much about who the professional is (ontology) as about what the professional knows (epistemology) (see also Dall'Alba \& Barnacle 2007). Thus, while the exigencies of professional regulation, maintenance of standards, patient safety and professional accountability require learning activities amenable to measurable outcomes, it remains important not to lose sight of the other half of the picture. What it means to become a professional must also be addressed by opening up spaces for learners to expand and deepen their understanding of self through discursive participation in communities of practice. 
Learning to be(come) a teacher, physiotherapist, and so on, involves transforming or 'turning around the self'. (Dall'Alba \& Barnacle 2007, p687, parentheses in original)

Fostering commitment, willingness to see different worlds of practice from multiple viewpoints, and care about the outcomes in a holistic sense; integrating knowing, acting and being (Prpic 2005, Solomon et al. 2006) is a crucial activity for practice educators committed to authentic learning. The questions are, 'How will I enable myself and others to engage in authentic learning?' 'How am I becoming transformed by my practice as an educator (as well as a practitioner)'?

This paper has used the concept of discourse communities to provide a framework of reflective questions through which practice educators can confront the dilemmas and contradictions that test them on a daily basis (Table 1).

Table 1 Reflective questions for practice educators within three discourse communities

\begin{tabular}{|c|c|c|}
\hline $\begin{array}{l}\text { Discourse community } 1 \text { : } \\
\text { Pedagogical }\end{array}$ & Discourse community 2: Critical & $\begin{array}{l}\text { Discourse community } 3 \text { : } \\
\text { Situated learning }\end{array}$ \\
\hline $\begin{array}{l}\text { What is my personal } \\
\text { philosophy of learning? }\end{array}$ & $\begin{array}{l}\text { Why do I do what I do as a } \\
\text { practice educator? }\end{array}$ & $\begin{array}{l}\text { What is authentic professional } \\
\text { learning in my practice? }\end{array}$ \\
\hline $\begin{array}{l}\text { Where do I position myself } \\
\text { in relation to learning as } \\
\text { product and/or process? }\end{array}$ & $\begin{array}{l}\text { How do I know I am good at } \\
\text { what I do as a practice } \\
\text { educator? }\end{array}$ & $\begin{array}{l}\text { How will I enable myself } \\
\text { and others to engage in } \\
\text { authentic learning? }\end{array}$ \\
\hline $\begin{array}{l}\text { What does it mean to be a } \\
\text { learner in the (my) } \\
\text { workplace? }\end{array}$ & $\begin{array}{l}\text { Can I reconcile competing value } \\
\text { systems and practise } \\
\text { authentically as a practice } \\
\text { educator? }\end{array}$ & $\begin{array}{l}\text { How am I being transformed } \\
\text { through my practice as } \\
\text { an educator? }\end{array}$ \\
\hline
\end{tabular}

These questions demonstrate how relentless change has had consequences, for the outcomes of professional practice, and for the professional learning that is integral to it at all levels. Increasingly, how professional practice is understood, what aspects of practice are valued over others, what counts as learning, and the nature of learning relationships are contested. Despite the tensions between them, as suggested at the start, the three discourse communities also overlap. Figure 1 illustrates this overlap using three dimensions of medical education identified by Harden et al. (1999).

'Doing the right thing' represents clearly defined, explicit, accessible aspects of practice that are the competence requirement for all practitioners. 'Doing the thing right' involves exercising academic and emotional intelligences through professional reasoning and judgement, acting ethically and practising authentically, both within and in spite of constraining structures and policies. 'The right person doing it' represents willingness to enquire continually into our own practice, to examine what we could do or could be(come), to be personally transformed through our own practice. The community of practice educators is positioned at the centre of what are surely complementary imperatives. They must not simply survive the ongoing bombardment of change. Rather, by bringing their own perspective to bear through participation, they may be active interpreters of change and how it may be shaped and optimised with and for coming generations of practitioners.

\section{Conclusions}

In 2013 the challenges for practice educators are greater than ever. Their ability to prepare pre-registration learners for the evolving demands of practice, to enhance the learning of 


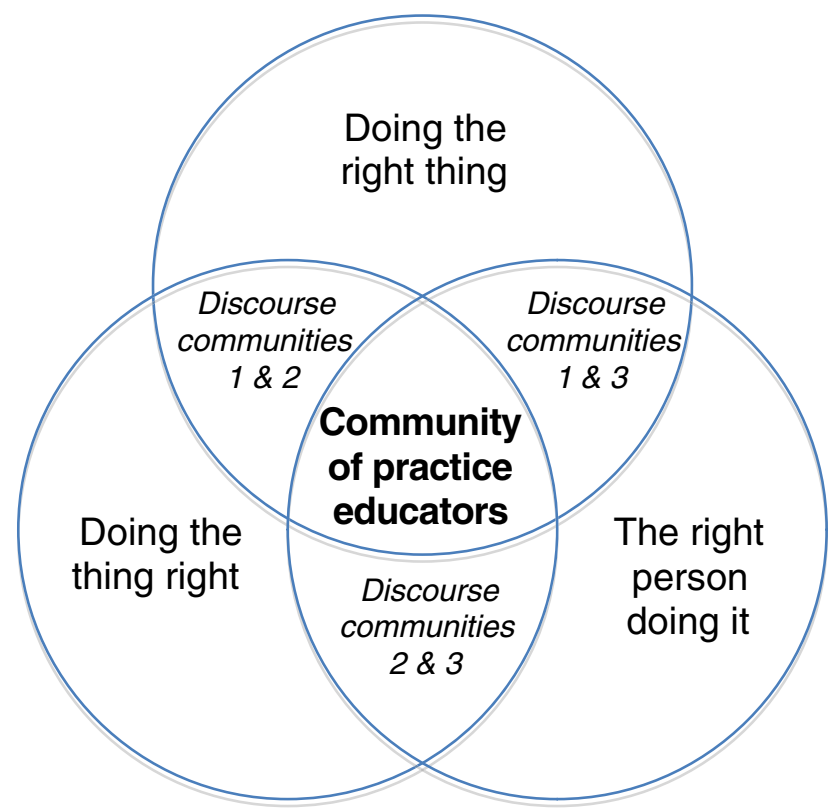

Figure 1 Positioning practice educators in relation to overlapping discourse communities

others further along the learning trajectory and to sustain their own continuing learning in the workplace, is subject to both individual agency and the social context of practice, locally and globally. Nevertheless, what Barnett $(2005$, p794) has identified as the central task and challenge for universities in an uncertain and unpredictable world does indeed make these potentially exciting times for practice educators. This task consists of enabling learners to develop 'the capacity to cope, to prosper and to delight in [such] a world for, ultimately, the only way, amid strangeness, to become fully human, to achieve agency and authenticity, is to have the capacity to go on producing strangeness by and for oneself'.

\section{References}

Ball, S.J. (2003) The teacher's soul and the terrors of performativity. Journal of Education Policy 18 (2), 215-228.

Barnett, R. (2005) Recapturing the universal in the university. Educational Philosophy and Theory 37 (6), 785-797.

Billett, S. (2001) Participation and continuity at work: a critique of current workplace learning discourses. Context, power and perspective: confronting the challenges to improving attainment in learning at work. Joint Network/SKOPE/TLRP International workshop 8-10 November 2001, Sunley Management Centre, University College of Northampton. Available at the informal education archives: http://www.infed.org/archives/e-texts/billett_ workplace_learning.

Billett, S. (2008) Learning through work: exploring instances of relational interdependencies. International Journal of Educational Research 47, 232-240.

Billett, S. and Somerville, M. (2004) Transformations at work: identity and learning. Studies in Continuing Education 26 (2), 310-326.

Boud, D. and Hager, P. (2012) Re-thinking continuing professional development through changing metaphors and location in professional practices. Studies in Continuing Education $34(1), 17-30$. 
Cross, V. (1994) From clinical supervisor to clinical educator: too much to ask? Physiotherapy 80 (9), 609-611.

Dall'Alba, G. and Barnacle, R. (2007) An ontological turn for higher education. Studies in Higher Education 32 (6), 679-691.

Dall'Alba, G. and Sandberg, J. (2006) Unveiling professional development: a critical review of stage models. Review of Educational Research 76 (3), 383-412.

Daloz, L. (1999) Mentor: guiding the journey of adult learners. San Francisco: Jossey-Bass.

Dewey, J. (1916) Democracy and education. New York: The Free Press.

Fuller, A., Hodkinson, H., Hodkinson, P. and Unwin, L. (2005) Learning as peripheral participation in communities of practice: a reassessment of key concepts in workplace learning. British Educational Research Journal 31 (1), 49-68.

Gardner, M.R. (1994) On trying to teach: the mind in correspondence. Hillsdale, NJ: Analytic Press.

Giddens, A. (1991) Modernity and self-identity: self and society in the late modern age. Cambridge: Polity Press.

Gilbert, T.P. (2005) Trust and managerialism: exploring discourses of care. Journal of Advanced Nursing 52 (4), 454-463.

Hager, P. (2004) Conceptions of learning and understanding at work. Studies in Continuing Education 26 (1), 3-17.

Harden, R.M., Crosby, J.R., Davis, M.H. and Friedman, M. (1999) AMEE Guide No. 14 Outcome-based education: Part 5 - From competency to meta-competency: a model for the specification of learning outcomes. Medical Teacher 21 (6), 546-552.

Health Education England (2013) Introducing Health Education England: our strategic intent, January 2013, NHS. Available at http://www.hee.nhs.uk/2013/01/31/our-strategic-intent/.

Hughes, C. (2002) Issues in supervisory facilitation. Studies in Continuing Education 24 (1), 57-71.

Lave, J. and Wenger, E. (1991) Situated learning - legitimate peripheral participation. Cambridge University Press.

Nicoll, K. and Edwards, R. (2012) Positioning adult educators in discourses of professional development. Studies in Continuing Education 34 (3), 233-249.

Ovens, A. (2002) Discourse communities and the social construction of reflection in teacher education. In Quality conversations, Proceedings of the 25th HERDSA Annual Conference, Perth, Western Australia, 7-10 July 2002, p512.

Prpic, J.K. (2005) Managing academic change through reflexive practice: a quest for new views. Available at http://conference.herdsa.org.au/2005/pdf/refereed/paper_425.pdf.

Rogoff, B. (1995) Observing sociocultural activity on three planes: participatory appropriation, guided participation, apprenticeship. In Sociocultural studies of mind (eds. J. V. Wertsch, A. Alvarez and P. del Rio), pp139-164. Cambridge University Press.

Romero, M.M.R. (1998) Educational change and discourse communities: representing change in postmodern times. Curriculum Studies 6 (1), 47-71 (at p53).

Schon, D. (1991) The reflective practitioner: how professionals think in action. Avebury: Ashgate Publishing. 
Solomon, N., Boud, D. and Rooney, D. (2006) The in-between: exposing everyday learning at work. International Journal of Lifelong Education 25 (1), 3-13.

Webster-Wright, A. (2009) Reframing professional development through understanding authentic professional learning. Review of Educational Research 79 (2), 702-739. 